\title{
Outcomes of a telemonitoring-based program (telEPOC) in frequently hospitalized COPD patients
}

\author{
Cristóbal Esteban ${ }^{1,2}$ \\ Javier Moraza' \\ Milagros Iriberri ${ }^{3}$ \\ Urko Aguirre 2,4 \\ Begoña Goiria ${ }^{5}$ \\ José M Quintana ${ }^{2,4}$ \\ Myriam Aburto' \\ Alberto Capelastegui' \\ 'Pneumology Department, Galdakao- \\ Usansolo Hospital, Galdakao, ${ }^{2}$ Red de \\ Investigación en Servicios Sanitarios y \\ Enfermedades Crónicas (REDISSEC), \\ Bilbao, ${ }^{3}$ Pneumology Department, \\ Cruces Hospital, Barakaldo, ${ }^{4}$ Research \\ Unit, Galdakao-Usansolo Hospital, \\ Galdakao, ${ }^{5}$ Primary Care Unit, \\ Barrualde Integrated Healthcare \\ Organisation (OSI-Barrualde), Spain
}

Correspondence: Cristóbal Esteban Servicio de Neumología, Hospital de Galdakao-Usansolo, 46 Barrio Labeaga, Galdakao, Vizcaya 48960, Spain Tel/fax +34944007002

Email cristobal.est@gmail.com
This article was published in the following Dove Press journal:

International Journal of COPD

24 November 2016

Number of times this article has been viewed

Background: The increasing prevalence of chronic diseases requires changes in health care delivery. In COPD, telemedicine appears to be a useful tool. Our objective was to evaluate the efficacy (in improving health care-resource use and clinical outcomes) of a telemonitoring-based program (telEPOC) in COPD patients with frequent hospitalizations.

Materials and methods: We conducted a nonrandomized observational study in an intervention cohort of 119 patients (Galdakao-Usansolo Hospital) and a control cohort of 78 patients (Cruces Hospital), followed up for 2 years (ClinicalTrials.gov identifier: NCT02528370). The inclusion criteria were two or more hospital admissions in the previous year or three or more admissions in the previous 2 years. The intervention group received telemonitoring plus education and controls usual care.

Results: Most participants were men (13\% women), and the sample had a mean age of 70 years, forced expiratory volume in 1 second of $45 \%$, Charlson comorbidity index score of 3.5 , and BODE (body mass index, airflow obstruction, dyspnea, and exercise capacity) index score of 4.1. In multivariate analysis, the intervention was independently related to lower rates of hospital admission (odds ratio [OR] 0.38, 95\% confidence interval [CI] 0.27-0.54; $P<0.0001$ ), emergency department attendance (OR 0.56, 95\% CI 0.35-0.92; $P<0.02$ ), and 30-day readmission (OR $0.46,95 \%$ CI $0.29-0.74 ; P<0.001$ ), as well as cumulative length of stay (OR $0.58,95 \%$ CI $0.46-0.73 ; P<0.0001)$. The intervention was independently related to changes in several clinical variables during the 2-year follow-up.

Conclusion: An intervention including telemonitoring and education was able to reduce the health care-resource use and stabilize the clinical condition of frequently admitted COPD patients.

Keywords: COPD, hospitalizations, telemonitoring program

\section{Introduction}

Traditional health care services are being overwhelmed by the impact of population aging, the increasing prevalence of chronic diseases in the population, and the demand for high-quality care in a patient-centered health system. COPD is a leading cause of morbidity and mortality worldwide, with two important points of impact: the use of health care resources that the disease implies, and the effect of the disease on the individual patient. Hospitalization has long been recognized as the main source of costs in this disease. ${ }^{1}$ At the same time, COPD exacerbation (eCOPD), especially episodes requiring hospitalization, has potentially severe consequences for the patient, such as loss of pulmonary function ${ }^{2}$ and quality of life $^{3}$ and an increase in mortality risk. ${ }^{4}$ 
All these facts and their economic consequences make it necessary to develop new care strategies. Telemedicine has emerged as a potential tool in a new model of care in COPD, as an alternative or complement to usual care. However, there is ongoing controversy about the efficacy of telemedicine in management of this disease. It is difficult to compare studies and draw definitive conclusions, given the heterogeneity of the cohorts studied, the limited number of patients included in some studies, differences between interventions used, and insufficient clarity in the description of the telemonitoring intervention, as well as the lack of clear primary objectives and short periods of follow-up in some cases. In fact, some review articles ${ }^{5}$ and editorials ${ }^{6}$ raise concerns or directly deny the efficacy of telemedicine as a tool in COPD management. In contrast, one review found a clear positive result regarding the rate of hospitalization and emergency department (ED) attendance. ${ }^{7}$ Therefore, it seems very important to extend the evidence base with well-designed studies to enable conclusive meta-analysis. The objective of this study was to evaluate the efficacy of a telemonitoring program, telEPOC, in a cohort of COPD patients with frequent hospitalizations.

\section{Materials and methods}

During May 2010 and July 2012, COPD patients were recruited in integrated health care organizations (IHOs) in two areas in Vizcaya. These two areas have different referral hospitals: Galdakao-Usansolo Hospital (Barrualde IHO), with a catchment population of 350,000, and Cruces Hospital (Ezkerraldea IHO), with a catchment population of 400,000 . The cohort from Galdakao formed the intervention group and that from Cruces the control group. Both were followed up for 2 years.

\section{Participants}

The inclusion criteria established were having COPD, the disease considered confirmed if postbronchodilator forced expiratory volume in 1 second $\left(\mathrm{FEV}_{1}\right)$ divided by forced vital capacity (FVC) was less than $0.7\left(\mathrm{FEV}_{1} / \mathrm{FVC}<70 \%\right)$, and having been admitted to hospital at least twice in the previous year or three times in the previous 2 years for an eCOPD. Exclusion criteria were having another significant respiratory disease, active cancer, or terminal illness, being unable to complete one or more of the measurements required for the study, unwilling to take part in the study, or not providing written informed consent.

With these requirements, patients were chosen from the databases of the hospitals. All the candidate patients and their caregivers were informed about the program in a general meeting, or individually during an admission, and invited to participate. If the patient agreed to take part, they were asked to sign the informed consent form. All data collected were kept confidential and the institutional review boards and ethics committees of the participating hospitals approved this study (Comisión de investigación del Hospital de GaldakaoUsansolo). The patients were required to be stable for at least 6 weeks before enrollment. All the participants had previously undergone spirometry, but the diagnosis of COPD was confirmed at the time of inclusion in the program.

\section{Usual care}

At the time of this study, patients were required not to be taking part in any specific clinical control program in the public health system. Patients were being routinely monitored through regular checkups with their primary care doctor and respiratory specialist. The frequency of these checkups in the respiratory surgery depended on the severity of the disease. Generally speaking, usual care implies a regular evaluation of the patient every 4-6 months. These regular checkups are not completely structured. In sum, it consists of a review of what has happened from the last review (eCOPD, hospitalizations), an evaluation of the current clinical and functional (spirometry) situation, an update of the respiratory treatment if it is necessary, a check of the inhalation technique (by a nurse), and a reminder of some general recommendation related to healthy habits (smoking, diet, weight, and physical activity). Generally, in the event of eCOPD, patients arranged a visit to their primary care doctor.

\section{Intervention}

The intervention program consisted of: 1) the provision of educational material about COPD (general information about the disease, its treatment, focusing on tobacco and inhaled medication, healthy lifestyle habits, and warning signs of eCOPD) by a respiratory nurse in two 30-minute sessions with the patient and caregiver, once on inclusion in the program, and again 1 year later; 2) training in using the device (smartphone) used for the telemonitoring; and 3) daily phone calls to enhance patient self-confidence during the first week of telemonitoring, and further calls as considered appropriate, progressively extending the interval between them, according to the capacity of the patient to manage on their own. Generally speaking, throughout the 2 years of the program, patients were given some advice on daily healthy habits, especially physical activity, in every phone call.

Written information about how the program ran and how to use the smartphone, as well as a contact telephone number, was provided to every patient and caregiver. 
Self-management plans related to eCOPDs were not included as part of the program, nor were any home visits. The implementation of this program had been previously explained to all primary care doctors involved in two general meetings.

The program was supported by a specialized respiratory nurse working full-time in Galdakao-Usansolo Hospital and two part-time respiratory specialists working on the program from Monday to Friday. During the evening and at weekends, a centralized call center (run by nonspecialized respiratory nurses) was in charge of the program.

The device used for the telemonitoring was a smartphone with specific software for the program. This software has two parts: 1) a questionnaire about the increase or not of the symptoms of the disease (cough, sputum, and dyspnea), plus a question about health status in the last 24 hours, from the last information sent ("In general, how would you characterize your health today?"; the three answers possible were "better", "as usual", and "worse"); and 2) physiological variables, ie, oxygen saturation and heart rate, which were sent by Bluetooth from the pulsioximeter to the smartphone. Temperature, steps/day, and respiratory rate were measured and typed into the smartphone program by the patient or carer.

Patients included in the telEPOC program were asked to submit information about their clinical condition on a daily basis. The daily data were sent by a secure Internet connection to a password-protected server and transferred to the Respiratory Department at Galdakao Hospital, where a nurse analyzed all the information from every patient. Baseline levels of each of the clinical measurements studied were established on a case-by-case basis, considering the patient's stable clinical condition at the time of inclusion in the program. These baseline data constituted the reference threshold for the daily measurements.

Once the patient's daily measurements had been received, they were automatically classified into one of three colorcoded levels (traffic lights), depending on the extent of deviation from the baseline values. The three levels were established by consensus among the research team, depending on the different combinations of measurements sent each day by a given patient: for example, a green alarm was cough increase or new appearance of mucus sputum; an orange alarm was a deterioration of every symptom or physiological measurement, including change of the sputum to "yellow"; a red alarm was any combination of deterioration of the variables recorded daily.

Once the patient data had been received, there were several possible courses of action. If all the data were classified as normal with respect to the previously established personalized thresholds, no action was taken. If the established threshold was exceeded an alarm was activated and a corresponding action plan was triggered. The first step was a nurse telephoning the patient or the caregiver. This phone call was used to confirm the alarm and its level of priority and attempt to resolve associated problems. If this action was not considered sufficient to address these problems and/or there were remaining concerns, the nurse had two options, depending on the severity of the alarm: waiting for the daily assessment of the patients by respiratory specialists (equivalent to a ward round) or contacting one of the respiratory specialists directly. At this point, it was the respiratory specialist who decided whether the patient should be referred to their primary care doctor, be assessed by a respiratory specialist of the program, or be sent to the hospital ED.

If it were decided that a patient should be assessed by a doctor in primary or specialized care, the program nurse contacted the doctor to arrange an appointment. An alert system warned the monitoring team if daily measurements had not been submitted.

\section{Study outcomes}

The first primary outcome of the study was the rate of hospitalization for eCOPD. We defined an eCOPD as a sustained worsening of a patient's COPD symptoms with respect to their established stable condition that was beyond normal day-to-day variations and needed specific treatment. In addition, the two other primary outcomes were length of hospital stay and rate of readmission within 30 days after index admission. Secondary outcomes of the study were rate of ED attendances and changes in clinical parameters (exercise capacity, limitations in daily life activities, healthrelated quality of life [HRQoL], anxiety, and depression). Deaths were also considered.

\section{Control group}

The control group received treatment according to usual care in our health system. That is based on regular checkups with the primary care doctor and respiratory specialist. These checkups followed a standard schedule of monitoring, with checkups every 4-6 months depending on the severity of the disease, and patients received unstructured information/ education about COPD. In brief, the key differences between the two groups were the telemonitoring system and the structured educational intervention. No additional intervention was carried out related to this study. 


\section{Baseline assessment}

The study protocol for both intervention and control cohorts included collection of a wide range of data before being included in the study, as well as each year during the follow-up. Specifically, data were collected on sociodemographic characteristics and smoking habits. The level of dyspnea was assessed using the modified Medical Research Council score. ${ }^{8}$ Comorbidities were determined by reviewing patients' medical records, and the Charlson Comorbidity Index was calculated. ${ }^{9}$ HRQoL was assessed using the validated Spanish version of the St George's Respiratory Questionnaire (SGRQ). ${ }^{10,11}$ The London Chest Activity of Daily Living (LCADL) scale ${ }^{12}$ and Hospital Anxiety and Depression Scale questionnaires ${ }^{13,14}$ were also completed by every patient to assess functioning and anxiety/depression, respectively.

Complete pulmonary function tests included forced spirometry, a bronchodilator test, and body plethysmography, as well as measurements of diffusion capacity for carbon monoxide and respiratory muscle strength. Standard values used were those established by the European Community for Steel and Coal. ${ }^{15}$ Two 6-minute walking tests (6MWTs) were performed, in accordance with American Thoracic Society guidelines. ${ }^{16}$ Further, the BODE (body mass index, airflow obstruction, dyspnea, exercise capacity) index was calculated. ${ }^{17}$ In addition, the intervention group used a pedometer every day.

Retrospective data from the 2 years prior to joining this study were retrieved from the hospital database for all patients. Specifically, the following data were collected: number of hospital admissions, length of hospital stay, readmission at 30 days after one hospitalization, and ED attendance.

\section{Follow-up}

Survivors were interviewed and underwent the aforementioned assessments every year during the follow-up period. No other interventions were performed related to this study.

\section{Data collection}

In the intervention group, data on hospitalizations and ED attendances during the study were collected in real time, patients having been instructed to report such events and daily monitoring ensuring regular assessment of patient status. Moreover, if a telemonitored patient did not submit the daily data, the system generated an alert, triggering a phone call from the nurse to ascertain why the data had not been sent. In addition, records were reviewed to identify hospitalizations and ED admissions of all participating patients (intervention and control groups) at the end of each year. The questionnaires and tests of pulmonary function and exercise capacity were also completed each year.

\section{Sample-size calculation}

Based on the results of a previous study, we estimated that we would need 85 patients in each group to achieve a power $(1-\beta)$ of $90 \%$ to detect a difference of 0.5 in the mean number of admissions between the control group (three admissions, standard deviation 1) and the intervention group (2.5 admissions, standard deviation 1$)$ with an $\alpha$-error of 0.05 .

\section{Statistical analysis}

Patient sociodemographic and clinical results were compared between control (H1) and intervention (H2) groups using the $\chi^{2}$ test (or Fisher's exact test if necessary) for qualitative variables and a two-sampled Wilcoxon test for continuous variables.

The main outcomes of the study were divided into two groups: variables related to the use of health care resources (COPD-related hospital admission, 30-day readmission, COPD-related ED attendance, and the cumulative length of hospital stay in cases when patients were admitted), and indicators that measured patients' HRQoL (SGRQ), functional limitations in daily life (LCADL total score), BODE index, anxiety and depression (HADS), and 6MWT distance. Means and their corresponding two-sided $95 \%$ confidence intervals (CIs; as well as medians with 25 th-75th percentiles for COPD hospitalization-management outcomes) were summarized by study group, at baseline, and at the end of the study period. Mean differences were also calculated between the two assessment points. We used Wilcoxon nonparametric tests for independent samples to compare between-group responses at each time point. Furthermore, the Wilcoxon signed-rank test was used for within-group before-and-after comparisons.

We fitted negative binomial models to estimate the effect of the telEPOC program on the following outcomes: 1) number of COPD hospital admissions, 2) number of COPD-related ED attendances, and 3) the cumulative length of stay observed during the program period. To this end, variables with $P<0.2^{18}$ in the unadjusted models were entered as independent factors into the backward-stepwise multivariate negative binomial models. To compare the performance of the nested models, various indicators were used: log likelihood, Akaike information criterion, and Bayesian information criterion. 
Likewise, generalized linear models were used to explore effects of the telEPOC program on the mean changes in HRQoL scores (SGRQ and LCADL total scales) and 6MWT distance. $R^{2}$ values were calculated to assess the overall variability explained by the variables included in the models. Finally, intention-to-treat analysis was conducted to assess the effect of the telEPOC program: we assumed that patients who dropped out during the follow-up returned to their previous data (for use of health care resources) and baseline values for clinical outcomes. All statistical analyses and plotting of figures were performed using R 3.2.0 release and SAS software, version 9.4 of the SAS System for Windows. $P$-values less than 0.05 were deemed statistically significant.

\section{Results}

A total of 198 patients were included in the study: 120 in the intervention group and 78 in the control group. One patient refused to participate in the intervention group and none in the control group. During the study period, 17 patients were withdrawn: in the intervention group, two declined to continue with the study, two did not fulfill the whole program, four were not able to complete all the assessments required for the study, two had cancer diagnosed during the first month, one was diagnosed with dementia, one underwent lung transplantation, and three were terminal during follow-up. In addition, one patient was dropped due to loss to follow-up. Nevertheless, only one patient declined to participate in the control group (Figure 1).

\section{Baseline characteristics}

General characteristics of the whole sample are summarized in Tables 1-3. The majority of the participants were men (13\% women), and the sample had a mean age of 70 years, $\mathrm{FEV}_{1} \%$ of $45 \%$, Charlson Comorbidity Index score of 3.5 , and BODE index score of 4.1.

In clinical variables, there were significant differences between the two cohorts, the intervention group having a more severe level of dyspnea and poorer LCADL and HADS

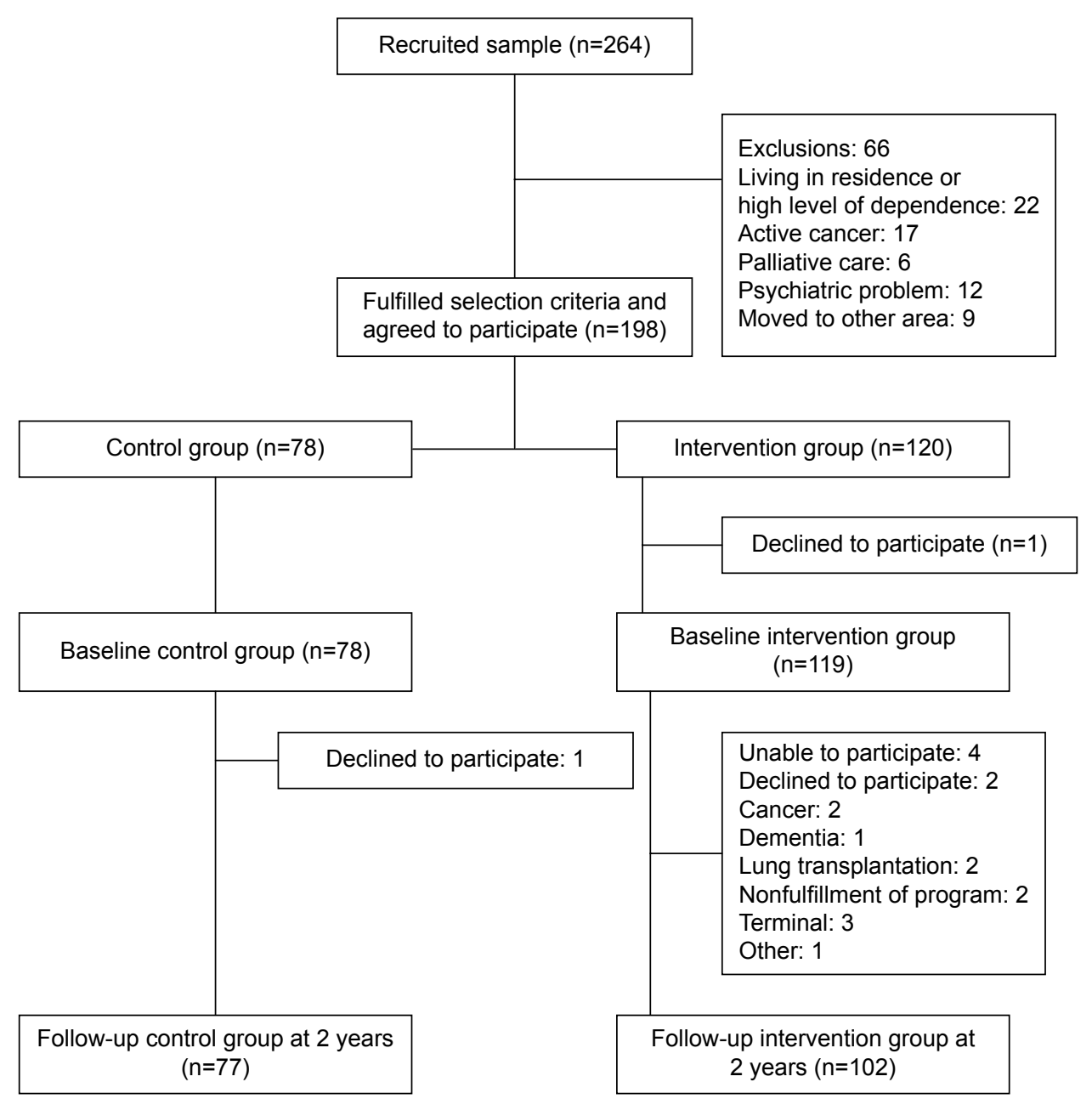

Figure I Flowchart of recruitment and follow-up process. 
Table I Sociodemographic and clinical descriptive data

\begin{tabular}{|c|c|c|c|c|}
\hline \multirow[t]{3}{*}{ Variable } & \multicolumn{2}{|l|}{ Hospital } & \multirow{3}{*}{$\begin{array}{l}\text { Total } \\
197\end{array}$} & \multirow[t]{3}{*}{$P$-value } \\
\hline & $\mathrm{HI}$ & $\mathbf{H} 2$ & & \\
\hline & $78(39.6)$ & $119(60.4)$ & & \\
\hline Sex & & & & 0.9 \\
\hline Male & 68 (87.2\%) & $103(86.6 \%)$ & I7| (86.8\%) & \\
\hline Age, years & $70.1(7.5)$ & $71.34(9.36)$ & $70.83(8.83)$ & 0.21 \\
\hline BMI & $27.78(5.05)$ & $26.99(4.8)$ & $27.3(4.9)$ & 0.46 \\
\hline BMI & & & & 0.4 \\
\hline$<25$ & $23(29.5 \%)$ & 39 (32.8\%) & $62(31.5 \%)$ & \\
\hline $25-30$ & $32(4 \mid \%)$ & $55(46.2 \%)$ & 87 (44.2\%) & \\
\hline$>30$ & $23(29.5 \%)$ & $25(2 \mid \%)$ & 48 (24.4\%) & \\
\hline Smoking status & & & & 0.5 \\
\hline Current smoker & 12 (I5.4\%) & $19(16 \%)$ & 31 (I5.7\%) & \\
\hline Ex-smoker & 65 (83.3\%) & 96 (79.8\%) & $160(81.2 \%)$ & \\
\hline Nonsmoker & $\mathrm{I}(\mathrm{I} .3 \%)$ & $5(4.2 \%)$ & $6(3.1 \%)$ & \\
\hline General health & & & & 0.01 \\
\hline Excellent & 0 & 0 & $0(0 \%)$ & \\
\hline Very good & $2(2.6 \%)$ & 0 & $2(1 \%)$ & \\
\hline Good & $8(10.3 \%)$ & 28 (23.5\%) & $36(18.3 \%)$ & \\
\hline Regular & 46 (55\%) & 51 (42\%) & 96 (48.7\%) & \\
\hline Bad & $20(25.6 \%)$ & $4 \mathrm{I}(34.5 \%)$ & 61 (31\%) & \\
\hline Modified MRC dyspnea scale & & & & 0.02 \\
\hline $0-1$ & 28 (35.9\%) & $27(22.7 \%)$ & 55 (27.9\%) & \\
\hline 2 & $22(28.2 \%)$ & 48 (40.3\%) & 70 (35.5\%) & \\
\hline 3 & $8(10.3 \%)$ & $25(21 \%)$ & $33(16.8 \%)$ & \\
\hline 4 & $20(25.6 \%)$ & $19(16 \%)$ & 39 (19.8\%) & \\
\hline \multicolumn{5}{|l|}{ Pulmonary function tests } \\
\hline $\mathrm{FEV}_{1}(\%)$ & $44.5(15.1)$ & $45.5(15.7)$ & $45.1(15.4)$ & 0.46 \\
\hline FVC (\%) & $74.3(17.8)$ & $72(19.1)$ & $72.9(18.5)$ & 0.34 \\
\hline Charlson Comorbidity Index & $3.5(2.1)$ & $3.5(1.7)$ & $3.5(1.9)$ & 0.74 \\
\hline Charlson Comorbidity Index & & & & 0.66 \\
\hline 1 & 14 (I7.9\%) & $16(13.4 \%)$ & $30(15.2 \%)$ & \\
\hline 2 & $15(19.2 \%)$ & $22(18.5 \%)$ & 37 (I8.8\%) & \\
\hline$>2$ & 49 (62.8\%) & $81(68.1 \%)$ & $130(66 \%)$ & \\
\hline BODE index & $3.9(2.2)$ & $4.3(2.5)$ & $4.1(2.4)$ & 0.34 \\
\hline
\end{tabular}

Note: Data expressed as $\mathrm{n}(\%)$ or mean (standard deviation).

Abbreviations: $\mathrm{HI}$, control group; $\mathrm{H} 2$, intervention group; BMI, body mass index; MRC, medical research council; $F E V_{1}$, forced expiratory volume in I second; FVC, forced vital capacity; BODE, body mass index, airflow obstruction, dyspnea, exercise capacity.

scores. Differences in HRQoL score, 6MWT distance, and BODE index score were not significant (Table 3).

With regard to use of health care resources prior to the start of the study, the rate of hospital admission $(P<0.03)$ and cumulative length of stay were both higher in the control group $(P<0.001)$, whereas no significant differences were found in the rates of ED attendance or 30-day readmission.

\section{Univariate analysis}

After 2 years, both cohorts showed a reduction in the rate of hospital admission $(P<0.001)$ but the reduction was significantly higher in the intervention group (1.14 vs 2.33 , $P<0.001)$. Further, in the control group, there were no significant differences in the rate of ED attendance, cumulative length of stay, or the rate of 30-day readmission at the end of follow-up compared to the 2-year period prior to the start of the study. In contrast, in the intervention group, we did find significant reductions in these variables during the study period.

In the clinical variables studied, we detected significant differences between the two cohorts in terms of changes between baseline and 2 years of follow-up in LCADL $(P=0.02)$, 6MWT $(P<0.001)$, BODE index $(P=0.008)$, and anxiety $(P=0.002)$ in favor of the intervention group. Though SGRQ scores differed by 3.65 between the groups, this difference was not significant $(P=0.07)$, and nor were there significant differences in depression scores $(P=0.06)$. Lastly, the mortality rate at 2 years was not significantly different in the two groups $(P=0.85)$. 
Table 2 Use of health care-resource outcomes: univariate analysis

\begin{tabular}{|c|c|c|c|c|c|}
\hline \multirow[t]{2}{*}{ Outcome variables } & \multicolumn{2}{|l|}{ HI (n=78) } & \multicolumn{2}{|l|}{$H 2(n=119)$} & \multirow[t]{2}{*}{$P$-value } \\
\hline & Mean $(95 \% \mathrm{Cl})$ & Median $\left(\mathbf{P}_{25}-\mathbf{P}_{75}\right)$ & Mean $(95 \% \mathrm{Cl})$ & Median $\left(\mathbf{P}_{25}-\mathbf{P}_{75}\right)$ & \\
\hline \multicolumn{6}{|l|}{ COPD hospital admissions } \\
\hline Preintervention & $3.9(3.5-4.4)$ & $3(3-4)$ & $3.4(3.1-3.8)$ & $3(2-4)$ & 0.03 \\
\hline Postintervention & $2.8(2.2-3.4)$ & $2(I-4)$ & I.I (0.7-I.5) & $0(0-1)$ & $<0.001$ \\
\hline Pre- vs postintervention & I.I (0.5-I.7) & $2(0-3)$ & $2.3(1.9-2.7)$ & $2(2-3)$ & $<0.001$ \\
\hline Trend $P$-value & $<0.001$ & & $<0.001$ & & \\
\hline \multicolumn{6}{|c|}{ COPD-related readmissions within 30 days $^{*}$} \\
\hline Preintervention & I.3 (0.9-I.7) & $\mathrm{I}(0-2)$ & I.I (0.7-I.4) & I (0-I.5) & 0.54 \\
\hline Postintervention & I.I (0.7-I.5) & $0(0-1.5)$ & $0.4(0.1-0.7)$ & $0(0-0)$ & 0.001 \\
\hline Pre- vs postintervention & $0.2(-0.3$ to 0.8$)$ & $0(-1$ to $I)$ & $0.7(0.3-1.1)$ & $I(0-I)$ & 0.09 \\
\hline Trend $P$-value & 0.38 & & 0.003 & & \\
\hline \multicolumn{6}{|c|}{ Visits to ED related to COPD exacerbation } \\
\hline Preintervention & $0.8(0.5-1)$ & $0(0-I)$ & I $(0.7-1.2)$ & $I(0-I)$ & 0.09 \\
\hline Postintervention & $0.9(0.6-1.2)$ & $0(0-1)$ & $0.6(0.3-0.8)$ & $0(0-1)$ & 0.02 \\
\hline Pre- vs postintervention & $-0.1(-0.1$ to 0.2$)$ & $0(-I$ to $I)$ & $0.4(0.1-0.6)$ & $0(0-1)$ & 0.006 \\
\hline Trend $P$-value & 0.42 & & 0.002 & & \\
\hline \multicolumn{6}{|l|}{ Cumulative total LOS $¥$} \\
\hline Preintervention & $39.5(31.6-7.3)$ & $32.5(20-46.5)$ & $21.7(\mid 6.2-27.1)$ & $14(8.5-26.5)$ & $<0.001$ \\
\hline Postintervention & $34.1(26.5-41.8)$ & $24(12-49)$ & $14.7(10.1-19.2)$ & $7.5(3.5-18.5)$ & $<0.001$ \\
\hline Pre- vs postintervention & $-5.32(-14.5$ to 3.8$)$ & $-3.5(-19$ to 14.5$)$ & $-7(-13.6$ to 0.4$)$ & $-6(-18$ to 3$)$ & 0.56 \\
\hline Trend $P$-value & 0.33 & & 0.006 & & \\
\hline
\end{tabular}

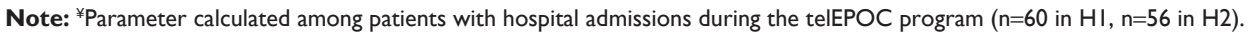

Abbreviations: $\mathrm{Cl}$, confidence interval; $\mathrm{P}_{25}, 25$ th percentile; $\mathrm{P}_{75}, 75$ th precentile; $\mathrm{HI}$, control group; $\mathrm{H} 2$, intervention group; ED, emergency department; LOS, length of stay.

Table 3 Clinical outcomes: univariate analysis

\begin{tabular}{|c|c|c|c|}
\hline \multirow[t]{2}{*}{ Outcome variables } & \multirow{2}{*}{$\frac{\mathrm{HI}(\mathrm{n}=\mathbf{7 8})}{\text { Mean }(95 \% \mathrm{Cl})}$} & \multirow{2}{*}{$\begin{array}{l}\mathrm{H} 2(\mathrm{n}=\mathrm{I} \mid \mathrm{9}) \\
\text { Mean }(95 \% \mathrm{Cl})\end{array}$} & \multirow[t]{2}{*}{$P$-value } \\
\hline & & & \\
\hline \multicolumn{4}{|l|}{ SGRQ total $(n=164)$} \\
\hline Baseline & $50.9(46.6-55.3)$ & $49.5(46-53)$ & 0.53 \\
\hline At end of telEPOC program & $52.1(47.5-56.6)$ & $47(43.4-50.6)$ & 0.08 \\
\hline Difference & $-1.15(-5$ to 2.7$)$ & $2.5(-0.03$ to 5$)$ & 0.07 \\
\hline Trend $P$-value & 0.4 & 0.03 & \\
\hline \multicolumn{4}{|l|}{ LCADL scale total $(n=164)$} \\
\hline Baseline & $21.2(18.1-24.3)$ & $24.1(21.8-26.5)$ & 0.04 \\
\hline At end of telEPOC program & $27.6(23.9-31.3)$ & $26.2(23.5-28.8)$ & 0.62 \\
\hline Difference & $-6.4(-10.1$ to -2.7$)$ & $-2(-3.5$ to -0.6$)$ & 0.02 \\
\hline Trend $P$-value & $<0.001$ & 0.007 & \\
\hline \multicolumn{4}{|l|}{ Six-minute walk test, $m(n=182)$} \\
\hline Baseline & 352.84 (332.15-373.53) & 311.14 (286.62-335.67) & 0.26 \\
\hline At end of telEPOC program & $302.87(281.68-324.07)$ & $305.47(280.5-330.45)$ & 0.2 \\
\hline Difference & $-49.97(-65.11$ to -34.83$)$ & $-5.67(-21.32$ to 9.8$)$ & $<0.001$ \\
\hline Trend $P$-value & $<0.001$ & 0.83 & \\
\hline \multicolumn{4}{|l|}{ BODE index $(n=182)$} \\
\hline Baseline & $3.6(3.1-4.1)$ & $4.3(3.8-4.7)$ & 0.12 \\
\hline At end of telEPOC program & $4.1(3.7-4.7)$ & $4.3(3.9-4.8)$ & 0.99 \\
\hline Difference & $0.6(0.2-1)$ & $0.03(-0.3$ to 0.3$)$ & 0.008 \\
\hline Trend $P$-value & 0.004 & 0.78 & \\
\hline \multicolumn{4}{|l|}{$\operatorname{HADS}(n=165)$} \\
\hline Baseline & $4.6(3.7-5.5)$ & $6(5.1-6.9)$ & 0.04 \\
\hline At end of telEPOC program & $5.6(4.7-6.6)$ & $6.1(5.3-6.9)$ & 0.51 \\
\hline Difference & $-1.1(-1.9$ to -0.2$)$ & $-0.08(-0.8$ to 0.7$)$ & 0.06 \\
\hline Trend $P$-value & 0.02 & 0.84 & \\
\hline Death at end of telEPOC program & & & 0.85 \\
\hline Yes, n (\%) & $13(16.7 \%)$ & $22(18.5 \%)$ & \\
\hline
\end{tabular}

Abbreviations: $\mathrm{HI}$, control group; $\mathrm{H} 2$, intervention group; Cl, confidence interval; HRQoL, health-related quality of life; SGRQ, St George's Respiratory Questionnaire; LCADL, London Chest Activity of Daily Living; BODE, body mass index, airflow obstruction, dyspnea, exercise capacity; HADS, Hospital Anxiety and Depression Scale. 


\section{Multivariate analysis}

In the multivariate analysis, being in the intervention group, ie, under the care of the hospital that implemented the telEPOC program, was independently associated with lower rates of hospital admission (incident rate ratio[IRR] 0.38, 95\% CI $0.27-0.54 ; P<0.0001$ ), ED attendance (IRR 0.56, 95\% CI $0.35-0.92 ; P<0.02$ ), and 30-day readmission (IRR 0.46, 95\% CI $0.29-0.74 ; P<0.001)$, as well as cumulative length of stay (IRR $0.58,95 \%$ CI $0.46-0.73 ; P<0.0001$ ) (Table 4).

With respect to clinical variables, again treatment at the hospital implementing the intervention was independently associated with positive changes or less deterioration in HRQoL and LCADL scores, 6MWT distance, and BODE index score during the 2-year study period (Table 5). Finally, results obtained from the sensitivity analysis and shown in Table 6 determine a favorable effect of the aforementioned program.

\section{Discussion}

The implementation of a 2-year program based on telemonitoring and education in a cohort of COPD patients with frequent eCOPD hospitalizations diminished the rate of hospital admission and length of stay during hospitalization, the rate of ED attendance for an ECOPD, and the rate of 30-day readmission. The program also had an impact on clinical variables.

\section{Use of health care resources}

Previous studies have provided some evidence of an effect of telemonitoring on health care-resource use. In a 6-month multicenter nonrandomized controlled study, the rate of hospitalization fell in the cohort of patients supported by telemonitoring, though this was in univariate analysis not adjusted for relevant variables. ${ }^{19}$ In a randomized clinical trial, a nearly $40 \%$ reduction in admissions was observed during 1 year of follow-up in a cohort of COPD patients with moderate-to-severe obstruction and one hospital admission the year before who were enrolled on a program based on education, self-management of eCOPD, and phone calls. ${ }^{20}$ In a randomized 1-year follow-up study including patients immediately after a hospital discharge, an integrated care program (consisting in a tailored plan managed with primary

Table 4 Use of health care-resource outcomes: multivariate analysis

\begin{tabular}{|c|c|c|c|}
\hline Model & $\beta$-estimate (SE) & IRR (95\% CI) & $P$-value \\
\hline \multicolumn{4}{|l|}{ COPD hospital admissions* } \\
\hline Intercept & $-0.552(0.848)$ & $0.576(0.109-3.033)$ & 0.515 \\
\hline Hospital (H2 vs $\mathrm{HI})$ & $-0.962(0.178)$ & $0.382(0.27-0.54 I)$ & $<0.000$ I \\
\hline BODE index & $0.184(0.038)$ & $1.203(1.117-1.295)$ & $<0.000$ I \\
\hline Previous COPD admissions & $0.174(0.042)$ & 1.19 (I.097-I.292) & $<0.0001$ \\
\hline \multicolumn{4}{|l|}{ Visits to ED related to COPD* } \\
\hline Intercept & $-1.246(1.231)$ & $0.288(0.026-3.21)$ & 0.311 \\
\hline Hospital (H2 vs $\mathrm{HI})$ & $-0.575(0.248)$ & $0.563(0.346-0.916)$ & 0.021 \\
\hline BODE index & $0.04(0.05 \mathrm{I})$ & $1.04 \mid(0.94 I-I .15)$ & 0.438 \\
\hline Previous ED visits related to COPD & $0.401(0.091)$ & $1.494(1.25 \mathrm{I}-1.784)$ & $<0.000$ I \\
\hline \multicolumn{4}{|l|}{ Cumulative total LOS** } \\
\hline Intercept & $2.054(0.199)$ & $7.8(5.279-1 \mathrm{I} .526)$ & $<0.000$ I \\
\hline Hospital ( $\mathrm{H} 2$ vs $\mathrm{HI})$ & $-0.545(0.119)$ & $0.58(0.459-0.732)$ & $<0.0001$ \\
\hline BODE index & $0.052(0.026)$ & $1.053(1.002-1.107)$ & 0.042 \\
\hline Previous cumulative LOS & $0.001(0.002)$ & $1.001(0.997-1.005)$ & 0.758 \\
\hline COPD admissions during telEPOC program & $0.263(0.021)$ & I.30I (I.249-I.354) & $<0.000$ I \\
\hline \multicolumn{4}{|l|}{ Readmissions* } \\
\hline Intercept & $-0.207(1.098)$ & $0.813(0.094-7.002)$ & 0.851 \\
\hline Hospital ( $\mathrm{H} 2$ vs $\mathrm{HI})$ & $-0.775(0.24 I)$ & $0.46 \mid(0.287-0.738)$ & 0.001 \\
\hline BODE index & $0.131(0.052)$ & $1.140(1.03-1.262)$ & 0.012 \\
\hline Previous readmissions & $0.126(0.05 I)$ & $1.134(1.026-1.253)$ & 0.013 \\
\hline \multicolumn{4}{|l|}{ Readmissions within 30 days* } \\
\hline Intercept & $-0.713(1.624)$ & $0.49(0.02-11.827)$ & 0.661 \\
\hline Hospital ( $\mathrm{H} 2$ vs $\mathrm{HI})$ & $-1.36 \mid(0.388)$ & $0.256(0.12-0.549)$ & $<0.0001$ \\
\hline BODE index & $0.229(0.082)$ & $1.258(1.072-1.476)$ & 0.005 \\
\hline Previous readmissions within 30 days & $0.123(0.116)$ & $1.131(0.901-1.419)$ & 0.288 \\
\hline
\end{tabular}

Notes: *Models adjusted by patient's sex and age and Charlson Comorbidity Index; **model adjusted by Charlson Comorbidity Index and HADS depression domain. Abbreviations: SE, standard error; IRR, incidence-rate ratio; $\mathrm{Cl}$, confidence interval; $\mathrm{HI}$, control group; $\mathrm{H}$, intervention group; BODE, body mass index, airflow obstruction, dyspnea, exercise capacity; ED, emergency department; LOS, length of stay; HADS, Hospital Anxiety and Depression Scale. 
Table 5 Clinical outcomes: multivariate analysis of outcome change

\begin{tabular}{|c|c|c|c|c|c|c|}
\hline & \multicolumn{2}{|l|}{ SGRQ } & \multicolumn{2}{|l|}{ LCADL } & \multicolumn{2}{|c|}{ 6-Minute walking test } \\
\hline & $\beta$ (SE) & $P$-value & $\beta$ (SE) & $P$-value & $\beta(\mathrm{SE})$ & P-value \\
\hline Intercept & $-15.342(3.367)$ & 0.001 & $-10.697(1.998)$ & $<0.0001$ & $76.994(37.325)$ & 0.04 \\
\hline Baseline domain & $0.337(0.074)$ & $<0.0001$ & $0.36(0.083)$ & $<0.0001$ & $-0.293(0.07 I)$ & $<0.0001$ \\
\hline \multicolumn{7}{|l|}{ Hospital } \\
\hline H2 (intervention) & $4.185(2.077)$ & 0.046 & $3.332(1.644)$ & 0.044 & $36.633(11.756)$ & 0.002 \\
\hline $\mathrm{HI}$ (control) & Reference & & Reference & & Reference & \\
\hline BODE index & $-0.763(0.556)$ & 0.172 & $-0.605(0.416)$ & 0.148 & $-6.591(3.638)$ & 0.072 \\
\hline \multicolumn{7}{|l|}{ Sex } \\
\hline Female & - & - & $-6.962(2.373)$ & 0.004 & - & - \\
\hline Male & - & - & Reference & & - & - \\
\hline$R^{2}$ & $14.62 \%$ & & $16.32 \%$ & & $16.6 \%$ & \\
\hline
\end{tabular}

Note: Positive $\beta$-estimate means improvement in HRQoL variables.

Abbreviations: SGRQ, St George's Respiratory Questionnaire; LCADL, London Chest Activity of Daily Living; SE, standard error; HI, control group; H2, intervention group; BODE, body mass index, airflow obstruction, dyspnea, exercise capacity; HRQoL, health-related quality of life.

care and access to a specialized nurse through a web-based call center) diminished the rate of readmission for eCOPD in the intervention group. ${ }^{21}$ In relation to the rate of ED attendance, a $41 \%$ reduction was observed in one study, ${ }^{20}$ while other research showed no significant differences ${ }^{22}$ or did not consider this outcome. ${ }^{23}$

In brief, previous studies have in general found a decrease in hospitalization and ED-attendance rates with telemonitoring. However, comparisons between studies are difficult because of their very different methodologies, in the widest meaning of the term "methodology". In our program, we observed a reduction in the rates of hospitalization for eCOPD, the length of hospital stay during hospitalizations for eCOPDs, and the rate of ED attendance, but again the profile of our patients (frequently hospitalized

Table 6 Intention to treat analysis of the effect of the telEPOC program in the measured outcomes

\begin{tabular}{lll}
\hline & $\beta(\mathrm{SE})$ & $P$-value \\
\hline Use of health care-resource outcomes & & \\
COPD hospital admissions & $-0.83(0.17)$ & $<0.00$ I \\
Visits to ED related to COPD & $-0.502(0.242)$ & 0.038 \\
Accumulative total length of stay & $-0.573(0.114)$ & $<0.00$ I \\
Number of readmissions & $-0.738(0.236)$ & 0.002 \\
$\quad$ Number of readmissions within 30 days & $-1.338(0.387)$ & 0.00 I \\
Clinical outcomes & & \\
SGRQ & $3.93(2.03)$ & 0.055 \\
LCADL & $3.39(1.62)$ & 0.038 \\
Six-minute walking test & $49.82(12.55)$ & 0.000 I \\
\hline
\end{tabular}

Notes: $\beta$ (SE) estimates compare the telEPOC program arm and the control arm. A negative $\beta$-estimate in the use of health care resources means an improvement in the health care-resource outcome. Values from the previous 2 years were applied to participants lost to follow-up. A positive $\beta$-estimate in the changes in clinical outcome parameters means an improvement in the respective clinical outcome. Values from the baseline visit were applied to participants lost to follow-up.

Abbreviations: SE, standard error; ED, emergency department; SGRQ, St George's Respiratory Questionnaire; LCADL, London Chest Activity of Daily Living.
COPD patients) was very different to that of participants in the aforementioned studies.

Notably, in all the studies mentioned herein, as in ours, telemonitoring was implemented as part of an integrated care program; therefore, isolating the impact of telemonitoring alone is not possible. To answer this question, $128 \mathrm{COPD}$ patients with at least one hospitalization during the previous year were included in the telemonitoring arm of the Telescot randomized trial. Over 1 year, no significant differences were observed in terms of time to first hospital admission or total number of days of admission in the intervention arm with respect to usual care. In this trial, usual care included education in self-management of eCOPDs, a written management plan together with a supply of antibiotics and steroids, and various levels of clinical support, depending on where the patient lived. ${ }^{23}$ The Telescot methodology was very similar to that of our study. However, some differences can be identified: the Telescot study was a randomized controlled trial managed through primary care with follow-up time of 1 year, while our study was an observational controlled study managed by a respiratory department in collaboration with primary care and with a 2-year follow-up period. The inclusion criteria were at least one hospital admission in the previous year in the Telescot study vs at least two hospital admissions in the previous year or three in the previous 2 years in our study. In the Telescot study, clinical care varied in intensity and the way it was organized across the four regions of Lothian, while such variation was not present in our study. The Telescot evaluated just the telemonitoring system vs usual care, unlike our approach, in which the intervention included telemonitoring and structured education. A key issue in the analysis of the results of all these studies is what was considered the level of usual care. Having a very high 
level of usual care could influence research results (COPDrelated admissions/year), reducing the likelihood of finding differences related to telemonitoring. ${ }^{24}$

After adjusting for the cumulative length of stay prior to inclusion in our program and the number of admissions during the 2 years of follow-up, we did find a shorter length of stay in the intervention group. This reduction in mean hospital stay is probably related to the earlier detection of eCOPD episodes that required admission, allowing prompt treatment and faster recovery, close monitoring after discharge from hospital, contributing to discharge being safer. On the other hand, patients had been treated by the respiratory specialist team of the program before the hospital admission, and hence the hospital admission implied a treatment failure, and this could imply a more severe eCOPD, which would explain a longer hospital stay in some cases. In another study, such differences were not found with respect to the control group. ${ }^{20}$

The efficacy of our program is supported by the reduction in the rate of another variable, not generally considered in previous studies, namely short-term readmission after hospitalization. This is a key indicator of quality of care and an area for improvement in COPD, the rates of 30-day readmission generally being high, at around $23 \% .{ }^{25}$

\section{Changes in clinical variables}

In relation to clinical variables, HRQoL is what has usually been analyzed in previous studies. One integrated program showed very notable changes in all domains of the SGRQ at 3 months of follow-up. ${ }^{26}$ The design of that study was very similar to ours, but we did not include self-management teaching techniques and the follow-up period was longer in our study. On the other hand, considering the studies mentioned that showed reductions in resource use, differences were found only in the impact subscale of the SGRQ after 1 year of follow-up, ${ }^{20}$ while in a 6-month study no benefits were detected using the Clinical COPD Questionnaire. ${ }^{19}$ To date, benefits of telemonitoring have not been clearly demonstrated in terms of HRQoL.

We studied several clinical variables, including daily life limitations and exercise capacity, as well as HRQoL. In general, we found significant differences between the intervention and control groups in favor of the intervention group, except in the case of HRQoL. Notably, the control group lost a mean of $50 \mathrm{~m}$ in the 6MWT during the follow-up period, whereas the intervention group lost a mean of just $6 \mathrm{~m}$ at 2 years.
Overall, these results suggest that our program directly or indirectly helps preserve some crucial aspects of functioning in COPD patients, such as exercise capacity and ability to perform activities of daily living. It is not possible to establish, however, whether these clinical differences between the intervention and control groups were caused by the reduction in the rate of hospitalization or were related to the promotion of physical activity in the education program. The mortality rate was high, as is to be expected in this type of patient, and there were no significant differences between the groups.

\section{Limitations and strengths}

This program has been extended to other hospitals and health care districts in the Basque public health system. However, the level of care offered in our system may differ from that offered in other countries, and hence it may not be possible to extrapolate our results to other health systems.

We are unable to determine which parts of the results are related to each part of the program (telemonitoring and education). Although the structured education was limited to one 30-minute session a year, phone calls could have influenced the level of education received by the patients. The patients included had been admitted at least twice before beginning the program and monitored in the outpatient respiratory clinics of the hospitals of Galdakao-Usansolo and Cruces, as well as by their primary care doctors, and in all these contacts with health providers information and education is provided about COPD. However, it is difficult to assess accurately the usual level of COPD-related knowledge of our patients. On the other hand, the two hospitals involved in the study are $20 \mathrm{~km}$ apart and provide a similar level of care to COPD patients. Admissions for other causes have not been evaluated, because that was not the aim of the study.

We consider our selection of COPD patients with a high rate of eCOPD admission to be a strength of this study, previous studies generally having included patients with one previous admission, not taking into account whether or not they had a history of frequent admissions. Further, many previous studies completed only 1 year of follow-up, while we extended this to 2 years, providing a longer-term perspective.

\section{Conclusion}

In COPD patients with frequent hospitalizations, adding a program based on daily telemonitoring and structured education to the usual care provided in our country had an impact on the use of health care resources (rates of admission for 
eCOPD, ED attendance, and short-term readmission, as well as the length of stay during admissions) and also on several clinical variables.

\section{Acknowledgments}

Grants were received from the Spanish Government Health Research Fund Fondo de Investigación Sanitaria (PI10/ 01716), Department of Health of the Basque Government (2010111011), and Kronikgune (KRONIK11/020). We thank Julia G Fenn for editing the manuscript. We are grateful for the support of the following people:

\section{Primary care participants}

Abando N, Abasolo A, Abaunza KA, Acaiturri R, Acha A, Albizu A, Aldazabal LM, Antón Diez-Caballero B, Antón Rollán AC, Arraibi I, Balentziaga JL, Bilbao Aguirre F, Bolinaga A, Calvo B, Catania B, Chirapozu JM, Dávila F, De Castro Pelegrin A, De los Bueis G, Delgado Casulleras JM, Durana MA, Echeguibel M, Etxebarri A, Ezquerra JM, Fernandez Martinez A, Gabiña VE, Gago Gómez F, García HernandoMJ, Geijo G, GerediagaE, GómezFuentesL, González Echave MA, González Martin G, González Rodríguez M, González Santiesteban R, González Silvares E, Gorostiza FJ, Gorroño JI, Intxaurza N, Intxausti I, Izaguirre AI, Jaka Z, Jáuregui L, Laboa I, Larrauri M, Lavín A, Lazcano L, López Fernández J, Llama Guerra AM, López Palacios VM, March JF, Marijuan L, Martín Beñaran JR, Martínez de la Cuadra M, Martinez Ortega C, Marzo Jurico E, Matthies N, Mendieta M, Menéndez Gaztan I, Millan MA, Minondo L, Molano MS, Odriozola M, Ortega García MB, Ortego Fernández-Retana A, Ortiz Cobo N, Oteiza L, Paino F, Peña Entrena C, Perez Urquijo AI, Pérez Rodrigo A, Prieto Casado J, Román Cabanillas A, Romaña ML, Rubiera A, Sagarminaga I, Salaverri G, Unzurrunzaga M, Uribarri MV, Urigoitia PL, Urionabarrenetxea I, Zubizarreta E.

\section{telEPOC Group}

Hospital Galdakao-Usansolo: Tovar MD, Díez R, Arrizubieta I, Aizpiri S, Sainz de Aja L, Gorordo M, Basualdo LV, García-Loizaga A, Aramburu A, Pascual S, Uranga A, Dorado S, Gorordo I, Ballaz A, Egurrola M, Gallardo Rebollal MS, Pulido E.

Hospital Cruces: Insausti M.

Hospital Santa Marina: Tavernero E.

Hospital Txagorritxu: Sobradillo P.

Hospital Basurto: Sanchez-Juez R.

Hospital Donostia: Laparra J.

\section{Consejo Sanitario}

Roca R.

\section{Osarean}

Llano J, Resino S, Alday A.

\section{Osakidetza}

Lopez-Arbeloa P, Rabanal S.

\section{Disclosure}

The authors report no conflicts of interest in this work.

\section{References}

1. Miravitlles M, Murio C, Guerrero T, Gisbert R. Costs of chronic bronchitis and COPD: a 1-year follow-up study. Chest. 2003;123:784-791.

2. Donaldson GC, Seemungal TA, Bhowmik A, Wedzicha JA. Relationship between exacerbation frequency and lung function decline in chronic obstructive pulmonary disease. Thorax. 2002;57:847-852.

3. Esteban C, Quintana JM, Moraza J, et al. Impact of hospitalisations for exacerbations of COPD on health-related quality of life. Respir Med. 2009;103:1201-1208.

4. Soler-Cataluña JJ, Martinez-Garcia MA, Román Sánchez P, Salcedo E, Navarro M, Ochando R. Severe acute exacerbations and mortality in patients with chronic obstructive pulmonary disease. Thorax. 2005;60: 925-931.

5. Bolton CE, Waters CS, Peirce S, Elwyn G. Insufficient evidence of benefit: a systematic review of home telemonitoring for COPD. $J$ Eval Clin Pract. 2011;17:1216-1222.

6. Jordan R, Adab P, Jolly K. Telemonitoring for patients with COPD. BMJ. 2013;347:f5932.

7. McLean S, Nurmatov U, Liu JL, Pagliari C, Car J, Sheikh A. Telehealthcare for chronic obstructive pulmonary disease: Cochrane review and meta-analysis. Br J Gen Pract. 2012;62:e739-e749.

8. Mahler DA, Ward J, Waterman LA, McCusker C, Zuwallack R, Baird JC Patient-reported dyspnea in COPD reliability and association with stage of disease. Chest. 2009;136:1473-1479.

9. Charlson ME, Pompei P, Ales KL, MacKenzie CR. A new method of classifying prognostic comorbidity in longitudinal studies: development and validation. J Chronic Dis. 1987;40:373-383.

10. Jones PW, Quirk FH, Baveystock CM. The St George's Respiratory Questionnaire. Respir Med. 1991;85:25-31.

11. Ferrer M, Alonso J, Prieto L, et al. Validity and reliability of the St George's Respiratory Questionnaire after adaptation to a different language and culture: the Spanish example. Eur Respir J. 1996;9: 1160-1166.

12. Garrod R, Bestall JC, Paul EA, Wedzicha JA, Jones PW. Development and validation of a standardized measure of activity of daily living in patients with severe COPD: the London Chest Activity of Daily Living scale (LCADL). Respir Med. 2000;94:589-596.

13. Zigmond AS, Snaith RP. The hospital anxiety and depression scale. Acta Psychiatr Scand. 1983;67:361-370.

14. Quintana JM, Padierna A, Esteban C, Arostegui I, Bilbao A, Ruiz I. Evaluation of the psychometric characteristics of the Spanish version of the Hospital Anxiety and Depression Scale. Acta Psychiatr Scand. 2003;107:216-221.

15. Quanjer PH, Tammeling GJ, Cotes JE, Pedersen OF, Peslin R, Yernault JC. Lung volumes and forced ventilatory flows. Eur Respir J. 1993;16:5-40.

16. ATS Committee on Proficiency Standards for Clinical Pulmonary Function Laboratories. ATS statement: guidelines for the six-minute walk test. Am J Respir Crit Care Med. 2002;166:111-117. 
17. Celli BC, Cote CG, Marín JM, et al. The body-mass index, airflow obstruction, dyspnea, and exercise capacity index in chronic obstructive pulmonary disease. $N$ Engl J Med. 2004;350:1005-1012.

18. Vittinghoff E, Glidden DV, Shiboski SC, McCulloch CE. Regression Methods in Biostatistics: Linear, Logistic, Survival, and Repeated Measures Models. New York: Springer; 2012.

19. Trappenburg JC, Niesink A, de Weert-van Oene GH, et al. Effects of telemonitoring in patients with chronic obstructive pulmonary disease. Telemed J E Health. 2008;14:138-146.

20. Bourbeau J, Julien M, Maltais F, et al. Reduction of hospital utilization in patients with chronic obstructive pulmonary disease: a disease-specific self-management intervention. Arch Intern Med. 2003;163:585-591.

21. Casas A, Troosters T, Garcia-Aymerich J, et al. Integrated care prevents hospitalisations for exacerbations in COPD patients. Eur Respir J. 2006;28:1-8.
22. Toledo P, Jiménez S, del Pozo F, Roca J, Alonso A, Hernandez C. Telemedicine experience for chronic care in COPD. IEEE Trans Inf Technol Biomed. 2006;10:567-573.

23. Pinnock H, Hanley J, McCloughan L, et al. Effectiveness of telemonitoring integrated into existing clinical services on hospital admission for exacerbation of chronic obstructive pulmonary disease: researcher blind, multicentre, randomised controlled trial. BMJ. 2013;347:f6070.

24. Antoniades NC, Rochford PD, Pretto JJ, et al. Pilot study of remote telemonitoring in COPD. Telemed J E Health. 2012;18:634-640.

25. Jencks SF, Williams MV, Coleman EA. Rehospitalizations among patients in Medicare fee-for-service program. N Engl J Med. 2009;360: 1418-1428.

26. Koff P, Jones R, Cashman J, Voelkel N, Vandivier R. Proactive integrated care improves quality of life in patients with COPD. Eur Respir J. 2009;33:1031-1038.

\section{Publish your work in this journal}

The International Journal of COPD is an international, peer-reviewed journal of therapeutics and pharmacology focusing on concise rapid reporting of clinical studies and reviews in COPD. Special focus is given to the pathophysiological processes underlying the disease, intervention programs, patient focused education, and self management protocols.

\section{Dovepress}

This journal is indexed on PubMed Central, MedLine and CAS. The manuscript management system is completely online and includes a very quick and fair peer-review system, which is all easy to use. Visit http://www.dovepress.com/testimonials.php to read real quotes from published authors.

Submit your manuscript here: http://www.dovepress.com/international-journal-of-chronic-obstructive-pulmonary-disease-journal 